\title{
RAPID PROTOTYPING OF OVERHEAD CRANE DYNAMICS FOR OPERATION USE
}

\author{
Janusz Szpytko, Jakub Schab \\ AGH University of Science and Technology, Faculty of Mechanical Engineering and \\ Robotics, al. Mickiewicza 30, PL 30059 Cracow, Poland, \\ Tel.+48126173103,Fax+4812 6173531,szpytko@agh.edu.pl
}

\begin{abstract}
The paper is presenting modelling approach oriented to overhead travelling cranes dynamics for the needs of exploitation studies. The subject of the article comprises building and some selected exploitation studies on the overhead crane carried out on the model in virtual environment for the needs of evaluating the technical state of the device. Copyright $(\mathcal{C} 2005$
\end{abstract}

Keywords: modelling, overhead crane, rapid prototyping, transportation.

\section{1. INTRODUCTION}

Automated overhead cranes are playing the crucial part in integrated manufacturing systems in load shifting within the working space and technological processes` support. To adapt the transport facilities to the changeable qualitative requirements of a user, it is vital to formulate the conditions of rational exploitation in the specified environmental conditions. The issue of rationalization comprises setting the nominal values of device's exploitation parameters, as well as the alarm signals that reflect unsatisfactory (owing to ineffective operation costs) or undesirable (possible breakdown or safety hazard) technical state of the device. To bring above to practice, it is necessary to work out the procedures that enable evaluation of the technical state of a device. This should be preceded by cause-effect analysis carried out on a group of the devices of the same class and working in the similar conditions, or on the virtual models of such devices. Today more and more interest in device modelling and simulation area has been shown towards multibody dynamics (Geradin et al, 2001; Bauchau, 1998; Murphy et al, 1993; Wen, 1999).
It is not an easy task to work out the procedures of device's technical state evaluation in the real condition mainly due to the device's characteristic features, operational conditions and unit production for variable user's requirements and environmental conditions (Szpytko, 1996). Therefore, it is necessary to take up steps that tend towards rapid prototyping of overhead cranes for the needs of exploitation studies oriented at formulating the conditions of the rational exploitation in the specified environment (Szpytko, 2004a).

The known models of overhead cranes based on the oriented mathematical description usually based on Lagrange equation (Al-Garni et al, 1995; Amatucci, 1997; Ho-Hoon, 1997; Ho-Hoon, 1998; Kiss et al, 1999; Veeke, 1999; Giua et al, 2000) are time consuming and describe in rather simplified manner the complexity of phenomena that occur during device operating movements.

The subject of the article comprises building and some selected exploitation studies on the overhead crane carried out on the model in virtual environment for the needs of evaluating the technical state of the device. 


\section{VIRTUAL MODEL OF OVERHEAD CRANE WITH RIGID BODY}

To build the overhead crane's model, DADS software has been applied (LMS). DADS, as well as ADAMS software (MD), represents the group of CAD/CAM software that supports engineers work concerning dynamics of mechanical system analysis.

The software has successfully found its application in several industrial branches as a rapid prototyping tool in design and manufacture, testing and optimization of mechanical systems (Figure 1). The algorithm of multibody dynamics in DADS environment has been shown in Figure 2.

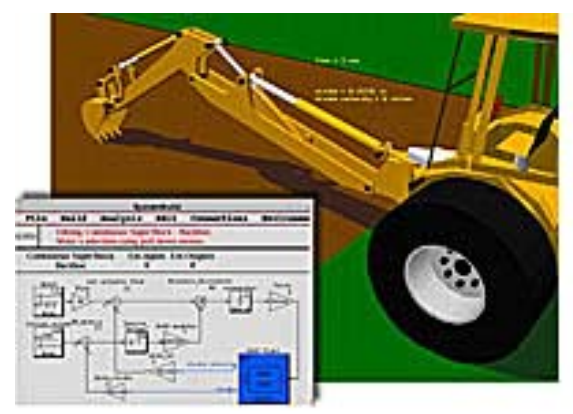

Fig 1. Examples of mechanical system models in DADS environment (LMS).

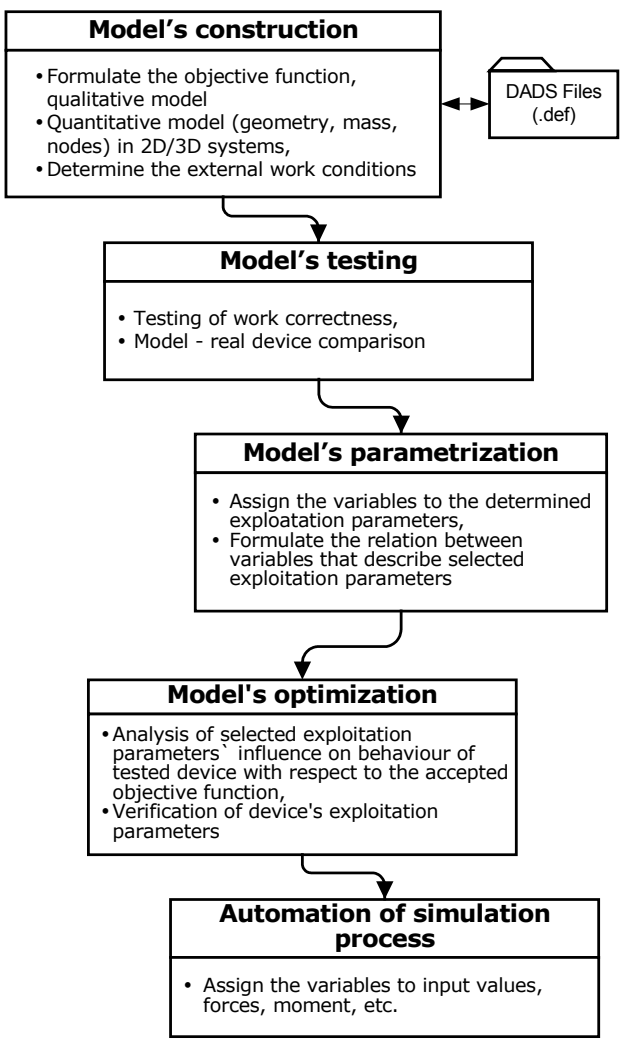

Fig.2. Algorithm of multibody dynamics model in DADS environment
Building of device's model consists of the following steps:

1. functional decomposition of a device into the units presented as solids (cylinders, cones, cubicoids, etc.), to which the geometrical (i.e. centre of gravity, moment of inertia) and material (selected from library or own definition: density, Young's modulus, Poisson coefficient, rigidity and elasticity) features has been assigned,

2. determination of the degrees of freedom within the distinguished device's units, as well as determination of the types of joints (rotational, sliding, cylindrical, planar, spherical, screw, and complex: gear, bushing) and friction (i.e. static, dynamical, others),

3. formulating the operation conditions regarding environmental influences (i.e. force, moments, contact between the distinguished units, others).

Overhead crane model in DADS environment has been presented in Figure 3. Within the model, device's operating subsystems have been distinguished (crane travelling, travelling crab and hoisting mechanisms), supporting subsystems (bridge and crab construction) and environment (rail track beam system).

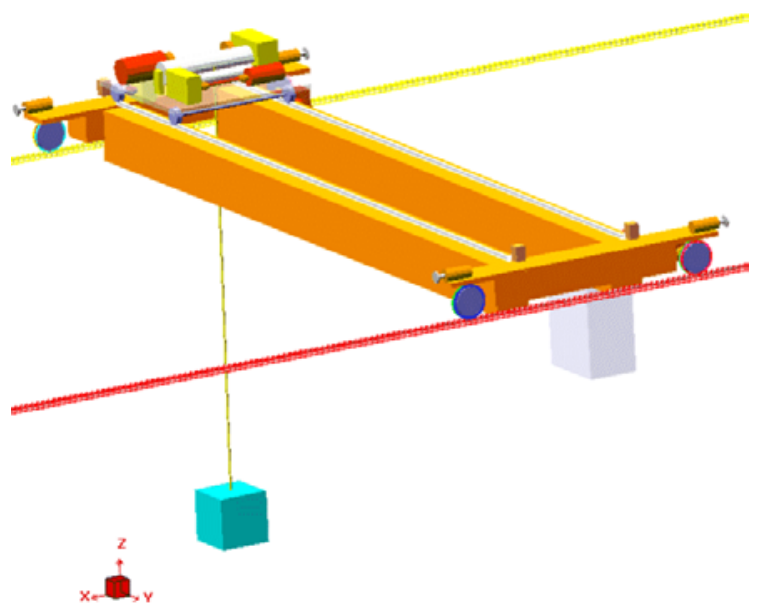

Fig. 3. Overhead crane model in DADS environment.

Owing to device's exploitation features special attention has been paid to power transmission system, wheel-rail system, load suspended on the rope. Exemplary characteristics of crane start-up, being used in exploitation tests have been shown in Figure 4.

The characteristic feature of device's model build in DADS environment is its insensitiveness to flexible unit's deformation. Such simplification of system description is correct provided the analysis concerns the devices with the similar number of rigid and flexible joints, in which influence of deformation can be omitted. Solids of distinguished units being the 
part of crane's model are of ideal rigidity and are insensitive to the bridge's deformation influenced by shifted load suspended on the robe.

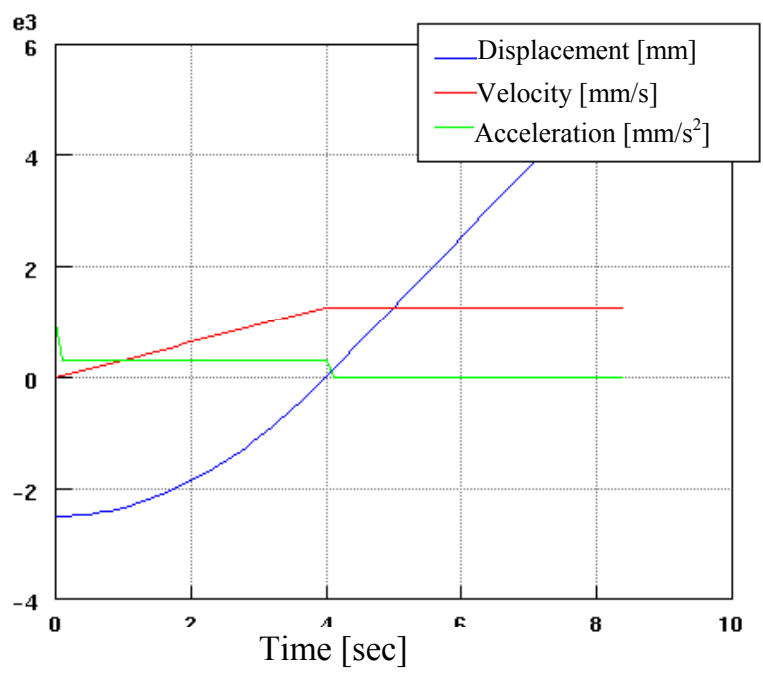

Fig. 4. Characteristics of crane start-up

Overhead cranes are devices, in which load-bearing structure is the unit which significantly influence the system's dynamics. Owing to the above, modelling and crane's tests in DADS environment can be regarded as acceptable only for bridges of high rigidity and re-dimensioned.

In the models of devices with flexible elements selected units of supporting subsystem are replaced by models that allow for connection between load and deformation. Here, the tools based on finite element method are used. The diagram of construction analysis by means of finite element method has been presented in Figure 5.

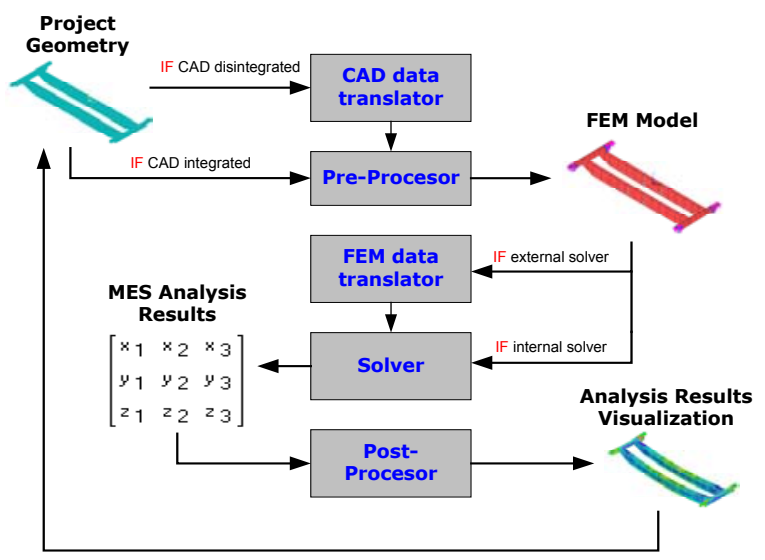

Fig. 5. Diagram of construction analysis by means of finite element method.

\section{OVERHEAD CRANE'S MODEL WITH FLEXIBLE ELEMENTS}

For the needs of exploitation tests, the overhead crane model with flexible elements has been elaborated. (Flexible Multibody Dynamics). Algorithm of model construction has been presented in Figure 6.

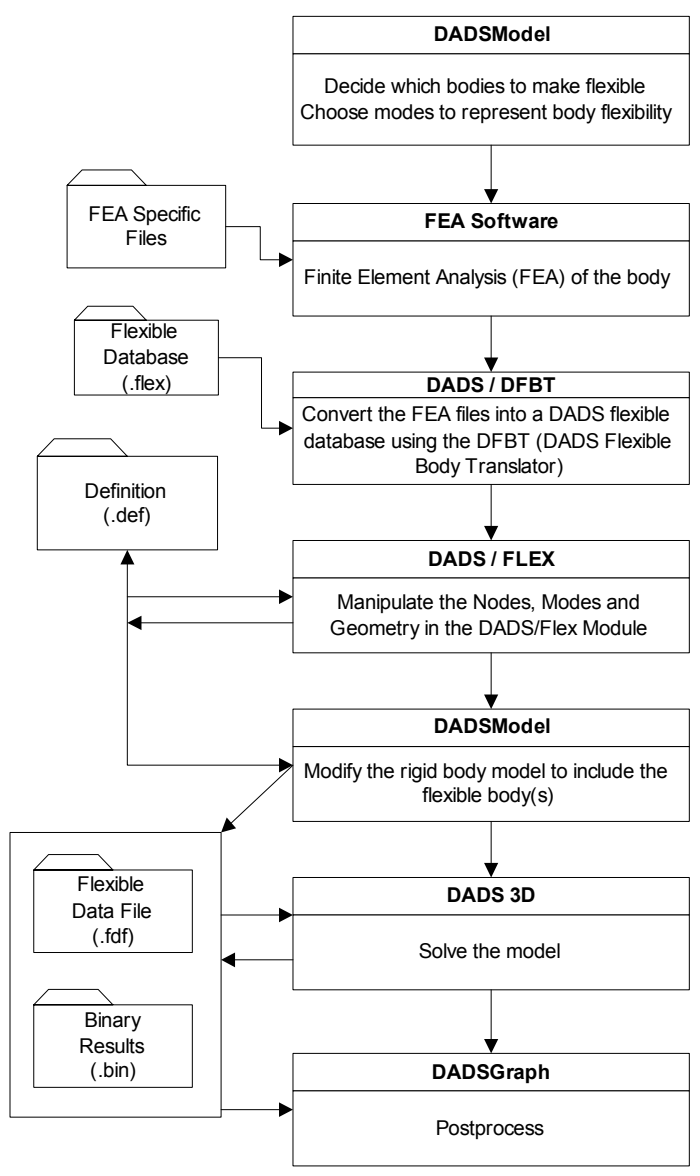

Fig. 6. Algorithm of model construction with use of flexible elements [DADS].

To prepare the device's model for dynamic analysis it is necessary to carry out static and modal analysis beforehand, by means of finite element method (MES). Analysis results obtained in that way include information about influence of static load and own vibrations of distinguished units on system's deformation, further they are converted to DADS/Flex and used during the simulation.

For overhead crane's bridge construction, finite element method based on ANSYS software has been applied (Figure 7). Construction's elements has been described by means of design language APDL (Ansys Parametric Design Language) which is fully parametric solid modelling language. Crane's bridge geometry was expressed by shell elements shell63, that are used for shell description, combining the features of bending elements with membrane type elements. 


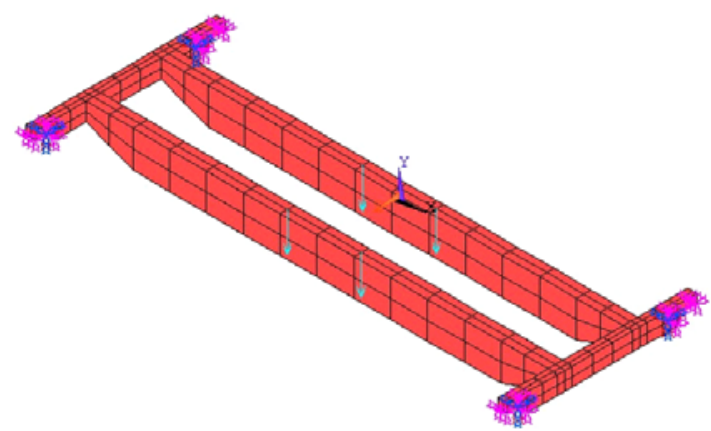

Fig. 7. Crane's bridge model with boundary conditions in ANSYS software.

Boundary conditions for bridge construction analysis by means of finite element method are set according to data conversion from ANSYS to DADS/Flex software. In case of static analysis, for all the mesh's nodes of finite elements construction combined with other systems' units, the unitary shift in each of 6 degree of freedom should be determined.

For those distinguished nodes, analysis requires to set their zero value of shift for all the degrees of freedom. Once the data (including bridge's rigidity matrix and the record of individual vibration frequency) has been prepared, they must be converted into DADS/Flex mode of DADS software by means of DFBT software (DADS Flexible Body Translator).

Adapting the model's mesh expressed in MES for the needs of simulation in DADS software is to prepare the key points that enable combining the flexible system with other units. It is possible to apply both internal and external interactions that represent environmental impact, as well as the changes in device's technical state. Model of overhead crane build in DADS/Flex environment by use of flexible elements has been presented in Figure 8.

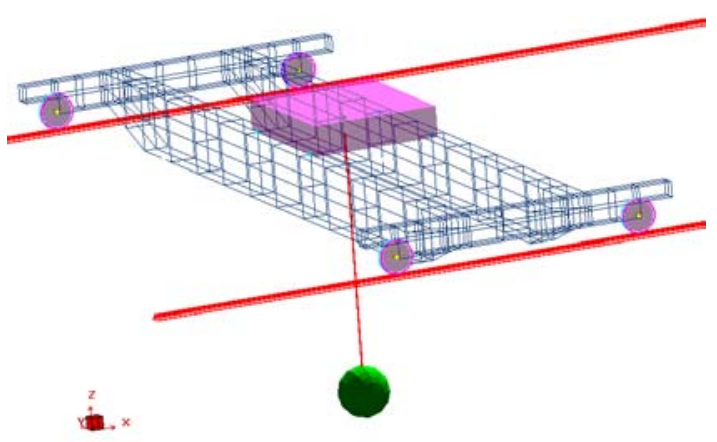

Fig. 8. Models of overhead crane build in DADS/Flex environment by use of flexible elements.
Pilot tests on two-girder overhead crane with hoisting capacity $\mathrm{Q}=12,5 \mathrm{t}$ and bridge span $\mathrm{L}=16 \mathrm{~m}$ have been carried out in DADS/Flex environment. The exemplary movement trajectory of device's centre of mass being observed in fixed coordinate system XOY combined with environment for the odd bridge wheel's position in horizontal plane $\beta_{1}=0,017 \mathrm{rad}$ has been presented in Figure 9. The phases being observed were crane's start-up and stabilized movement.

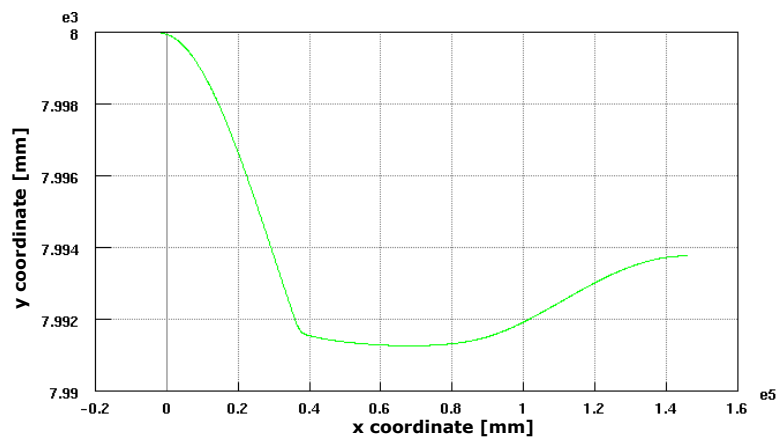

Fig. 9. The exemplary movement trajectory of crane's centre of mass being observed in fixed $\mathrm{XOY}$ coordinate system.

Figure 10 illustrates the changes of forces that interact with the distinguished bridge's wheel during bridge's movement along the rail track, where: $F_{n}$ vertical force, $F_{t}$ - driving force, $F_{a}$ - side horizontal force, $F_{x}-$ component horizontal force in $\mathrm{OX}$ direction, $\mathrm{F}_{\mathrm{y}}$ - component horizontal force in $\mathrm{OY}$ direction (Figure 11).

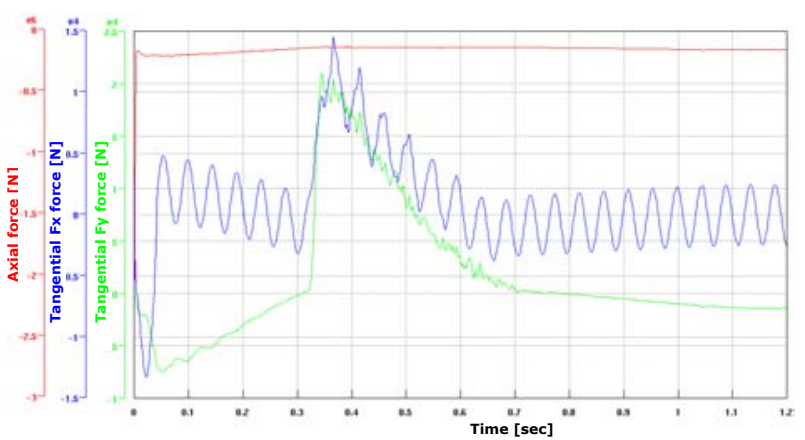

Fig. 10. Forces that interact with the distinguished crane bridge's wheel.

\section{FINAL REMARKS}

For the needs of crane exploitation studies, the virtual model of real device with hoisting capacity $\mathrm{Q}=12,5$ $\mathrm{t}$ and bridge span $\mathrm{L}=16 \mathrm{~m}$ has been elaborated. Device's models have been done in DADS environment for the bridge with ideal rigidity and elastic deformation. 

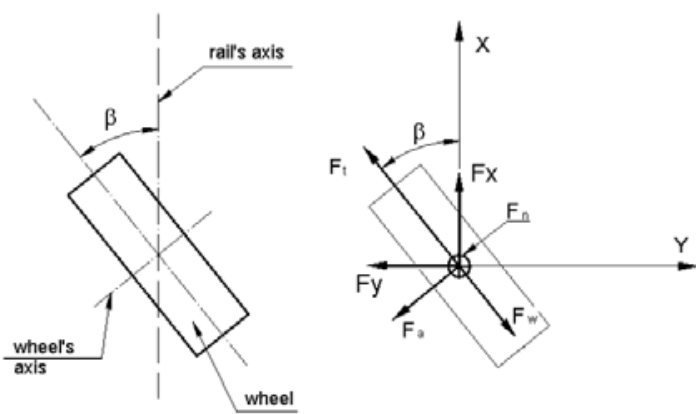

Fig. 11. Forces' distribution interacting with $i$-th crane wheels

Pilot studies that have been carried out on device's model enabled the qualitative evaluation. Moreover, the possibilities of qualitative analysis of different types of phenomena that might occur during exploitation have been acknowledged. The elaborated model requires to work out the method of its verification with the real model. It enables multioriented analysis of crane's exploitation parameters, as well as the changes analysis during the simulated crane's operation with regard to the environmental conditions.

The realisation of the investigation programme of the virtual model in total (or on selected subsystems) requires: to design the device model, to work out the methodology and the tools useful for monitoring selected exploitation parameters of the device (input supply products, output products), and to adjust the device model (Figure 12). The device model adjustment is a complex problem demanding proper selection of output device products, which are sensitive to the exploitation parameters significant to the formulated investigation target. Through model adjustment we understand such identification procedures, which make possible change of exploitation parameters of the model interactivity with digital investigation results (output products). The output products of the real and virtual models as a result of the device operation movements must be similar (both in qualitative and quantitative aspects).

The integrated modelling approach of complex transportation devices together with the monitoring system of selected exploitation parameters on the real object produce new challenges in the field of shaping and supervision, and their technical state. It has been specified that the presented approach is possible in practise [Szpytko, 2004b].

This paper has been financially supported by central budget on science for the years 2005-07 as the research project.

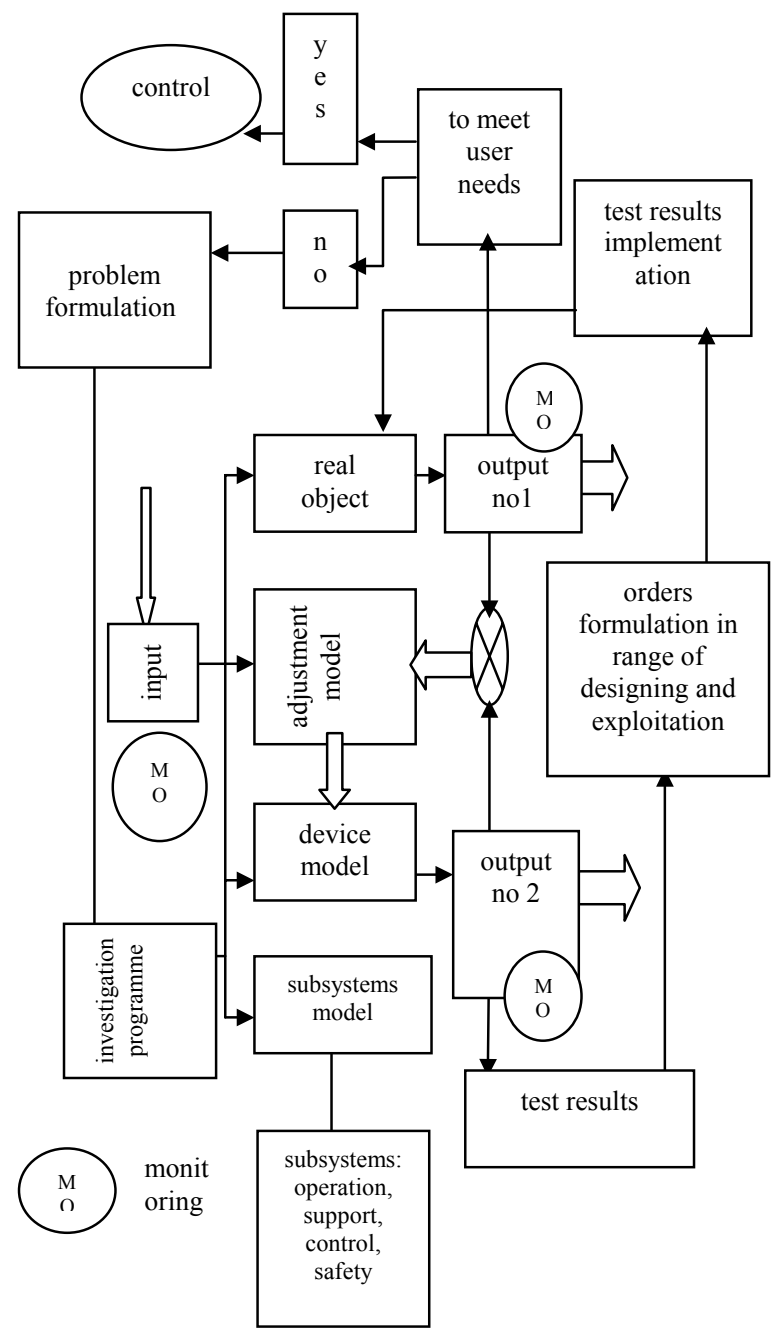

Fig. 12. Model of rapid exploitation investigations of the large dimensional type devices

\section{REFERENCES}

Al-Garni A.Z., Moustafa K.A.F., Nizami J. (1995). Optimal Control of Overhead Cranes. Control Eng. Practice, 3, 1277-1284.

Amatucci E., Bostelman R., Dagalakis, Tsai T. (1997). Summary of modeling and Simulation for NIST RoboCrane Applications. Proc. Deneb International Simulation Conference and Technology Showcase, Detroit, MI.

Bauchau, O.A. (1998). Computational Schemes for Flexible, Nonlinear Multi-Body Systems. Multibody System Dynamics, 2.

DADS Revision 9.6, Documentation.

Geradin, M. and Cardona, A. (2001). Flexible Multibody Dynamics: A Finite Element Approach. J. Wiley \& Sons, New York.

Giua A., Sanna M., Seatzu C. (2000). Modeling and control of 3D overhead cranes. 3rd IMACS Symp. on Mathematical Modeling, Vienna.

Ho-Hoon L. (1997). Modeling and Control of a 2Dimensional Overhead Crane. 61 Proc. of the ASME Dynamic Systems and Control Division, ASME Winter Annual Meeting, 535-542. 
Ho-Hoon L. (1998). Modeling and Control of a Three-Dimensional Overhead Crane. ASME Trans., J. of Dynamic Systems, Measurement, and Control, 120 (4), 471-476.

Kiss B., Levine J., Mullahaupt P. (1999). Modelling, Flatness and Simulation of a Class of Cranes. Periodica Polytechnica Ser.El. Eng., 43 (3), 215225.

LMS International Inc., http://www.lmsintl.com.

MD Mechanical Dynamics Inc., http://www.adams.com

Murphy S., Wen J.T., Saridis G.N. (1993). Modeling and Simulation of the Dynamics of Geared, Flexibly - Jointed Cooperating Manipulators. International Handbook on Robotic Simulation Systems, Ed. by D. Wloka, John Wiley \& Sons, NY.

Szpytko J. (1996). Integrated supervision system of the chosen exploitation parameters of the large dimensional rails' handling device on the automated overhead crane example. UMM Monographies, 46, Cracow.

Szpytko J. (2004a). Kształtowanie procesu eksploatacji środków transportu bliskiego. Monografia, Biblioteka Problemów Eksploatacji, ITE, Kraków - Radom.

Szpytko J. (2004b). Integrated decision making supporting the exploitation and control of transport devices. Monograph, UWND AGH, Kraków

Veeke H., Ottjes J.A. (1999). Problem oriented modeling and simulation. Proceedings of Summer Computer Simulation Conference (SCSC 1999), Chicago.

Wen J.T., Wilfinger L.S. (1999). Kinematic Manipulability of General Constrained Rigid Multibody Systems. IEEE Transaction on Robotics and Automation, 15 (3). 